\title{
An Easily Accessible Microfluidic Chip for High-Throughput Microalgae Screening for Biofuel Production
}

\author{
Shubhanvit Mishra ${ }^{1}$, Yi-Ju Liu ${ }^{2}$, Chi-Shuo Chen ${ }^{3, *(\mathbb{D})}$ and Da-Jeng Yao ${ }^{1,4,5, *(\mathbb{D})}$ \\ 1 Institute of Nano Engineering and MicroSystems, National Tsing Hua University, Hsinchu 30013, Taiwan; \\ shubhanvit@gmail.com \\ 2 Food Industry Research and Development Institute, Hsinchu 300193, Taiwan; lyj20@firdi.org.tw \\ 3 Department of Biomedical Engineering and Environmental Sciences, National Tsing Hua University, \\ Hsinchu 30013, Taiwan \\ 4 Department of Power Mechanical Engineering, National Tsing Hua University, Hsinchu 30013, Taiwan \\ 5 Department of Engineering and System Science, National Tsing Hua University, Hsinchu 30013, Taiwan \\ * Correspondence: chen.cs@mx.nthu.edu.tw (C.-S.C.); djyao@mx.nthu.edu.tw (D.-J.Y.)
}

Citation: Mishra, S.; Liu, Y.-J.; Chen, C.-S.; Yao, D.-J. An Easily Accessible Microfluidic Chip for High-

Throughput Microalgae Screening for Biofuel Production. Energies 2021, 14 , 1817. https://doi.org/10.3390/ en14071817

Academic Editor: José Carlos Magalhães Pires

Received: 28 February 2021

Accepted: 20 March 2021

Published: 24 March 2021

Publisher's Note: MDPI stays neutral with regard to jurisdictional claims in published maps and institutional affiliations.

Copyright: ( $\odot 2021$ by the authors Licensee MDPI, Basel, Switzerland. This article is an open access article distributed under the terms and conditions of the Creative Commons Attribution (CC BY) license (https:// creativecommons.org/licenses/by/ $4.0 /)$.

\begin{abstract}
Microalgae are important green energy resources. With high efficiency in fixing carbon dioxide, microalgae are broadly applied for biofuel production. Integrating various cultivation parameters, we applied ultraviolet (UV) mutagenesis, one of the most common approaches, to induce genomic mutation in microalgae and thus enhance the production of lipid content, but the screening process is convoluted and labor-intensive. In this study, we aimed to develop an accessible microfluidic platform to optimize the biofuel production of microalgae. Instead of traditional lithography, we designed hanging-drop microfluidic chips that were fabricated using a cheap computer numerical control (CNC) micro-milling technique. On each chip, we cultured in parallel Botryococcus braunii, one of the most common freshwater microalgae for biofuel production, in sets of ten separated hanging drops ( $\sim 30 \mu \mathrm{L}$ each); we monitored their growth in each individual drop for more than 14 days. To optimize the culturing conditions, using drops of varied diameter, we first identified the influence of cell density on algae growth and lipid production. After introducing UV-induced random mutations, we quantified the lipid content of the microalgae in situ; the optimized UV-C dosage was determined accordingly. In comparison with wild-type B. braunii, the results showed increased biomass growth (137\%) and lipid content (149\%) of the microalgae mutated with the desired UV process. Moreover, we showed a capacity to modulate the illumination on an addressed chip area. In summary, without using an external pump system, we developed a hanging-drop microfluidic system for long-term microalgae culturing, which can be easily operated using laboratory pipettes. This microfluidic system is expected to facilitate microalgae mutation breeding, and to be applied for algae cultivation optimization.
\end{abstract}

Keywords: biofuel; microfluidic; microalgae; UV mutagenesis

\section{Introduction}

Global warming, caused by $\mathrm{CO}_{2}$ emissions and the depletion of fossil fuels, has necessitated the search for sustainable and renewable energy sources [1]. In the past decade, biofuel has attracted great attention among researchers as a promising renewable energy source as it can be used to replace petrol and diesel while remaining carbon neutral [2,3]. Biodiesel can be produced from oil-containing crops [4]. As oil-containing crops require large land areas, the generation of biodiesel from high-oil-containing crops can, however, be the cause other problems, such as food scarcity [5]. Further, the use of farm land for biofuel production can cause increased emissions of greenhouse gases, which are emitted during the land use changes [6]. Under these circumstances, microalgae can be considered as a promising feedstock for biodiesel production, as they have a greater growth rate and lipid content than agricultural crops [3]. Botryococcus braunii is a green alga that is 
characterized by its ability to produce hydrocarbon-rich oil up to $61 \%$ of its dry mass [7-9]. B. braunii has attracted substantial interest as a potential species for the production of biofuels [1]; when the extracted hydrocarbon-rich oil from B. braunii is cracked, which is a process of catalytic and thermal degradation of long-chain hydrocarbons to form usable shorter-chain hydrocarbons, it yields petrol $67 \%$, aviation fuel $15 \%$ and diesel distillate $15 \%$, which proportions are similar to the gasoil fraction of crude oil; it is hence considered to be an effective candidate for third-generation biofuels.

Various microalgae studies have been conducted on culturing the cells in laboratoryscale flasks, open-raceway ponds or closed photobioreactors [10-12]. These studies significantly contribute to the understanding of basic algal biology and the selection of strains for oil production, and explore various culture parameters such as light intensity, light cycle [13], temperature [14], nutrient concentration [15], $\mathrm{CO}_{2}$, and $\mathrm{pH}$ [13]. In the development of any optimization of biofuel production, two limitations can hamper the progress. Firstly, because of intensive labor requirements and high operating costs, high-throughput screening is difficult using conventional photobioreactors [16]. Secondly, in conventional photobioreactors, it is challenging to maintain the culture conditions in a consistent and precise manner [16]. In recent decades, many microfluidic-based techniques have been developed that are capable of providing well-controlled culture conditions to optimize algal growth and lipid productivity [17]. For instance, recent studies have demonstrated the usefulness of devices with microchambers in the study of bacteria, as in the following: algae that are used in a micro-scale bioreactor for the automated culture and density analysis of microorganisms [18]; a fully automatic and programmable microfluidic device that enables parallel culture of cells [19]; the cultivation of microalgae in a droplet-based condition for the rapid screening of algal growth [20-22]; and simple chamber-based microfluidic devices for the quantification of lipid content in microalgae under varied stress conditions [23]. These studies helped to identify optimal conditions for microbial growth $[19,20,23]$.

In this work, we aimed to develop an easily accessible platform for the high-throughput screening of microalgae with rapid growth and a high lipid content. In addition, UV mutagenesis and various modulations of culture parameters, such as cell density and intensity of illumination, were integrated into this system to achieve culture optimization for the production of microalgae biofuel.

\section{Materials and Methods}

\subsection{Microalgae Culture}

Botryococcus braunii (AL20016, UTEX 2441) was supplied by Bioresource Collection and Research Centre (BCRC) in the Food Industry Research and Development Institute (FIRDI), Taiwan. It was cultivated in Bold-3N medium, which was prepared with double-distilled water $(\mathrm{ddH} 2 \mathrm{O})$ and various inorganic salts were added as per standard protocol [24]. Both experimental and stock cultures were kept in a biochemical incubator at $20 \pm 1{ }^{\circ} \mathrm{C}$, with a 12:12 h light/dark cycle (intensity of 1500 lux) provided by Warm White LED (WISVA OPTOELECTRONICS HH-S60F010-5050-12 WW) with a regulated intensity control switch. The cell cultures were shaken three times a week without aeration. Culture stock was maintained in $20 \mathrm{~mL}$ volume, and the cell density reached approximately $1.8 \times 10^{5}$ cells $/ \mathrm{mL}$ in 14 days.

\subsection{Chip Design and Fabrication}

Microfluidic hanging-drop devices were made using a computer numerical control (CNC) micro-milling system (Roland MDR-40A) as described elsewhere [25]. The devices were composed of two polystyrene layers (Figure 1A) of $25 \times 75 \mathrm{~mm}$. The thickness of the upper layer was $1.5 \mathrm{~mm}$, and it was used to make the inlet and outlet; the lower layer was also made of polystyrene which was $2 \mathrm{~mm}$ thick and consisted of a channel (thickness: $1200 \mu \mathrm{m}$ ) with opening wells at the bottom (Figure 1A). The chip used to study the effect of cell density on cell growth consisted of $13 \times 4$ opening wells with diameters of 1.1, 1.5 and $1.8 \mathrm{~mm}$. For the other tests, the chip consisted of $13 \times 4$ opening wells of diameter $1.1 \mathrm{~mm}$. 
For the assembly of the hanging-drop device, the fabricated layer was first immersed in ethanol solution $(75 \%)$ and cleaned with an ultrasonic cleaner for $30 \mathrm{~min}$ to remove any residual particles formed during fabrication. After cleaning, both the upper and bottom layers were assembled using adhesive tape $(0.05 \mathrm{~mm}, 300 \mathrm{LSE}, 3 \mathrm{M})$ which was cut using a laser-cutting instrument (C180II GCC, LaserPro). The outlet was made with the upper part of a pipette tip ( $1 \mathrm{~mL}$, diameter $4.5 \mathrm{~mm}$, height $5 \mathrm{~mm}$ ). The outlet was bonded with poly(dimethylsiloxane) (PDMS) and cured at $60^{\circ} \mathrm{C}$ for $90 \mathrm{~min}$. The base stand for the chips were also made from PDMS, cast using a laser-cut polystyrene mold, and cured at $90{ }^{\circ} \mathrm{C}$ for $60 \mathrm{~min}$. To study the effect of light on the growth, we placed this chip on a holder stand made of black opaque polystyrene sheet (thickness $3 \mathrm{~mm}$ ) to block the light in the desired region (Figure 1A).

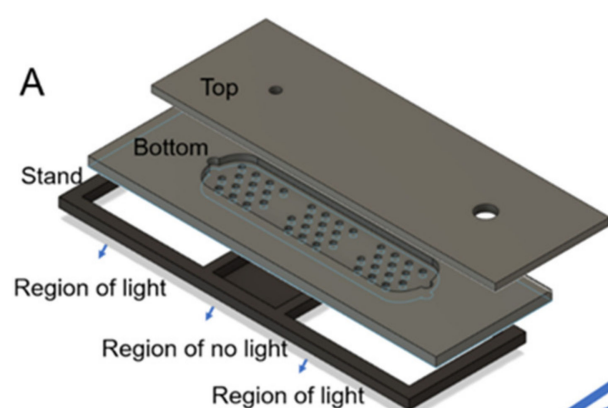

Region of light

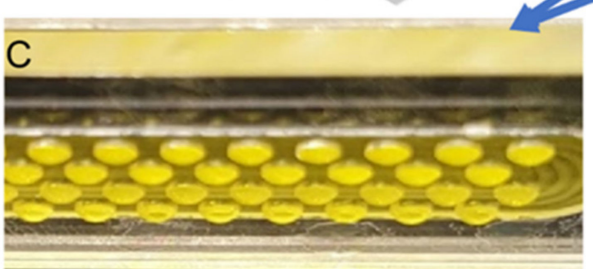

$2000 \mu \mathrm{m}$

E

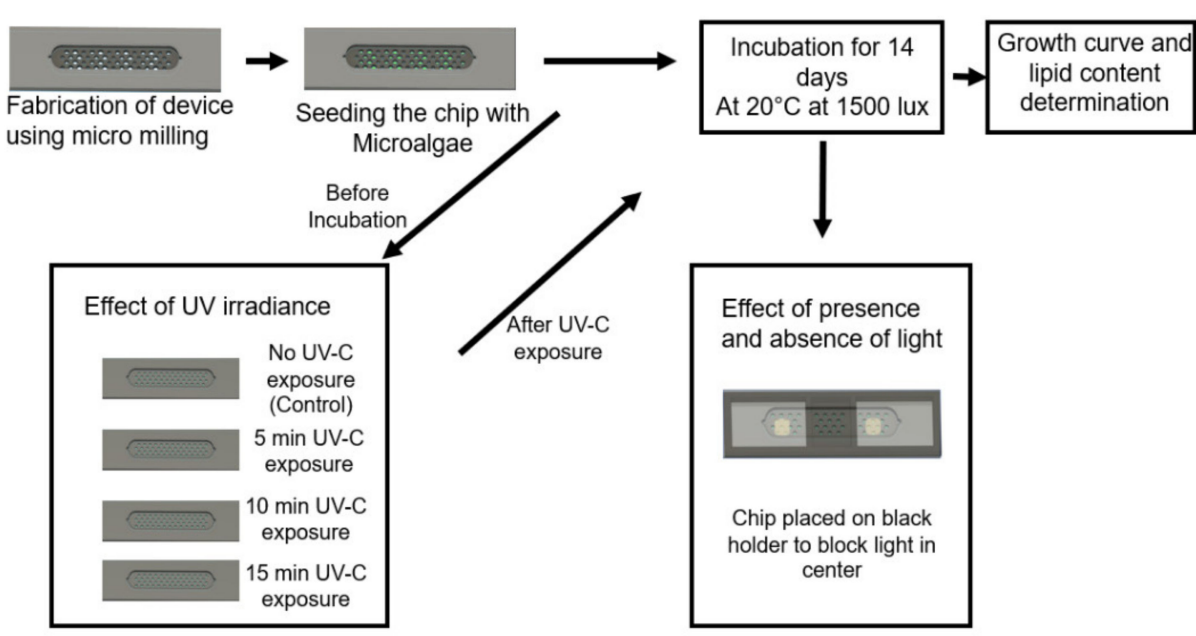

Figure 1. Illustration of the chip design. (A) Layout of a chip used to study the effect of light. The chip holder consists of three regions, two of which were exposed to light and one was an unexposed region. (B) Image of an actual assembled chip. (C) A chip filled with yellow dye shows the formation of a hanging drop formed on the bottom of the chip through the well (scale $=1 \mathrm{~mm}$ ). (D) Schematic illustration of the hanging-drop chip operation. (E) Schematic diagram to summarize the experimental design. 


\subsection{On-Chip Microalgae Culturing}

All cell seeding was performed in a sterilized laminar-flow hood. The chips were sterilized with UV-C light for $30 \mathrm{~min}$ before use. The chip was filled with ethanol solution $(75 \%)$ using a standard pipette. Then a culture medium $(900 \mu \mathrm{L})$ with algal cells (density $17 \times 10^{4} \mathrm{cell} / \mathrm{mL}$ ) was injected through the inlet. The cell suspension uniformly distributed the cells within the microchannel and allowed the cells to fall into the wells to form hanging drops. After the cells settled into the hanging drops for $30 \mathrm{~min}$, the microchannel was washed with fresh medium three times to remove the residual cells that were unable to fall into the well. After the washing step, the channel was filled with fresh medium $(950 \mu \mathrm{L})$. The chips were then placed in an incubator at $20 \pm 1{ }^{\circ} \mathrm{C}$, in warm white light with a $12: 12 \mathrm{~h}$ light:dark cycle and an intensity of 1500 lux for 14 days.

\subsection{Analysis of the Microalgae Growth Rate}

The growth of B. braunii inside the hanging-drop chip was characterized by measuring the intensity of chlorophyll autofluorescence of cells over time as in the existing literature [26]. The microalgae were imaged using an epi-fluorescent microscope (Eclipse Ti, Nikon Instruments, Inc., Japan) equipped with a filter set (TXRED, excitation at $559 \mathrm{~nm}$, emission at $630 \mathrm{~nm}$ ) every two days. To measure the growth rate, we selected 20 samples in each chip from a well with a specific diameter. The total intensity as a sum of chlorophyll autofluorescence was measured with image analysis software (Image J, NIH, USA). Large images (Figure 2A) of each chip (field area $13 \mathrm{~mm} \times 40 \mathrm{~mm}$ ) were acquired using a microscope with an automatic stage and stitched together afterward.

\section{A}

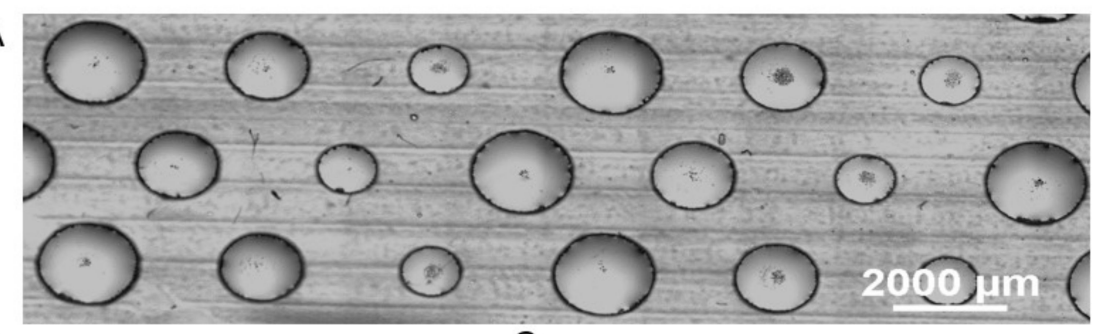

B

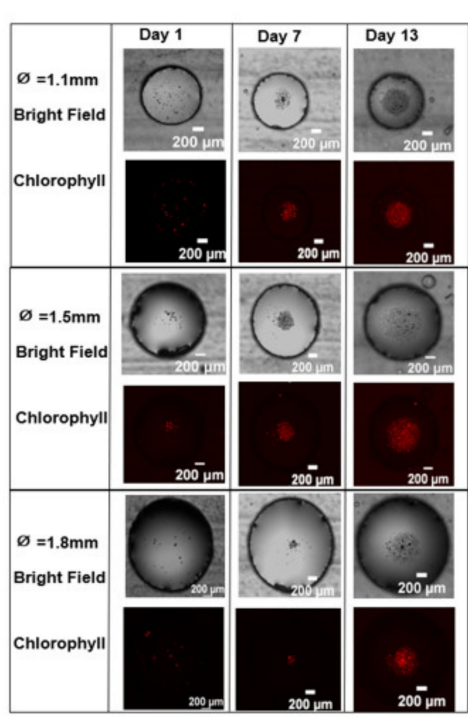

C

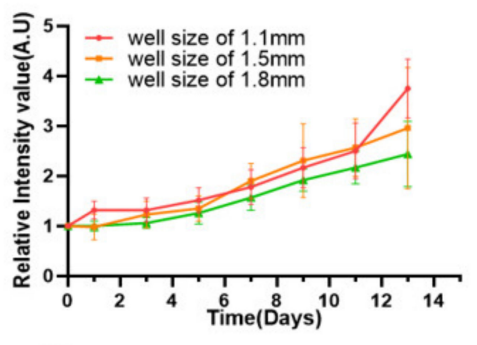

D

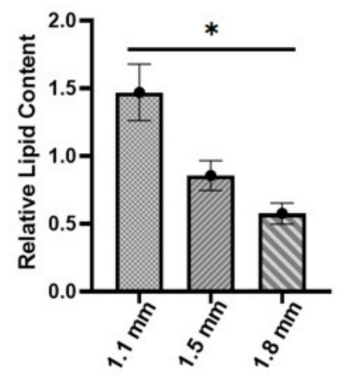

Figure 2. The microalgae cultured in the chip with three well diameters. (A) Bright-field image showing the formation of algal cell aggregated on a chip within the wells of sizes 1.1, 1.5 and $1.8 \mathrm{~mm}$ on its seventh day of culture. (B) Representative time-lapse bright field and chlorophyll $(\lambda=645 \mathrm{~nm})$ images showing the increased cell count (day 1, day 7 and day 13); the cell aggregations were observed. (C) Growth curve measured using the value of total chlorophyll intensity at wavelength $645 \mathrm{~nm}$. (D) Quantification analysis of lipid content in wells of varied diameter ( ${ }^{*}$ indicated $p$-value $<0.05$, $n=54$ ). 


\subsection{Microalgae Lipid Quantification}

To analyze and to quantify the lipid content, we utilized fluorescence staining (Nile red) [16]. Nile red, a lipid-soluble fluorescent dye that binds to neutral lipids, has been shown to stain B. braunii oil efficiently in both the extracellular matrix and intracellular oil bodies, and has been used to accurately evaluate the oil content in B. braunii [27]. For the lipid quantification, we stained the cells with Nile red fluorescent dye (concentration $10 \mu \mathrm{g} / \mathrm{mL}$ dissolved in dimethyl sulfoxide solution $10 \%$ ) on the fourteenth day of culture. To quantify the fluorescence, we used a microscope (Eclipse Ti, Nikon Instruments, Inc.) equipped with a filter set (TXRED, excitation at $559 \mathrm{~nm}$, emission at $630 \mathrm{~nm}$ ); the intensity sum was measured with image analysis software (Image J). The lipid content percentage was calculated by finding the difference between the intensities before and after staining, then dividing the difference by the initial intensity.

\section{Results and Discussion}

\section{Measurement of Growth Rate In Situ and Quantification of Lipid Content of B. braunii}

To study the influence of the cell density on the microalgae, we performed experiments with the hanging-drop chip using wells of varied diameter $(1.1,1.5,1.8 \mathrm{~mm})$. The growth rate after culture for 14 days in the chip was measured by taking the mean value of the total chlorophyll intensity ( $n=54$, from three independent experiments). Within the same chip, we managed the seeding density in each well by varying the diameter of the well. After seeding, we noticed that the range of seeding density, based on the total intensity, varied from $2.96 \pm 0.327$ to $7.08 \pm 0.430$ (A.U.) according to the increasing diameter of the well. The growth of microalgae was monitored and calculated using the total fluorescent intensity of chlorophyll in each well (Figure 2B,C). On day 14, we found that the total chlorophyll signal in the well with a diameter of $1.8 \mathrm{~mm}$ was 4.86 times that in the well with a diameter $1.1 \mathrm{~mm}$ and 5.65 times that in the well with a diameter $1.5 \mathrm{~mm}$; once normalized with the initial chlorophyll signal on day 0 , we noticed that the growth rate of microalgae in a small hanging drop was greater than that in larger drops (Figure 2C). The signals of chlorophyll are strongly associated with biomass production [28]. Being limited by the volume of the hanging drop, the biomass cannot be directly evaluated as for a large-scale approach [16]; our data indicated a greater biomass production with increased cell density. We also noticed a more rapid formation of microalgae aggregation in the smaller droplets. The lipid content on the fourteenth day of microalgae culture in wells of diameter $1.1 \mathrm{~mm}$ showed Nile red signals 1.70 and 2.53 times those from wells of $1.5 \mathrm{~mm}$ and $1.8 \mathrm{~mm}$, respectively (Figure 2D). It has also been reported that the fluorescent intensity of cells stained with Nile red and the lipid content in B. braunii as determined with a conventional solvent extraction system show a linear relation $\left(R^{2}=0.998\right)$ [27].

These results indicate that in our hanging-drop chip, the large cell density improves cell growth and lipid production. In a small hanging drop, the microalgae accumulated quickly at the bottom because of the strong curvature of a small drop. We speculate that the spatial distribution of a microalgae community is associated with the alteration of microalgae physiology. The increased cell growth observed in our study confirms previous findings, which indicated that a large cell density is associated with increasing proliferation, such as an algae bloom in nature [29]. Previous authors also reported that small colonies have advantages over dispersed microalgae, such as greater affinities for light and nutrients, and subsequently greater rates of growth [30]. In a conventional culture flask, the cell density and nutrition limitation are coupled so that the effects of a single factor are not determined easily. Here, with our developed chip, algae of varied cell density were cultured in separated wells under the same experimental conditions of nutrition; the results confirm the influence of cell density on cell growth.

A greater lipid content of microalgae was observed in a $1.1 \mathrm{~mm}$ well, which might also be associated with increased cell density. We speculated that cell aggregation may facilitate the formation of biofilm matrix and high lipid content. During photosynthesis, extracellular polymeric substances (EPS) are released by algae, and algae attach together 
with EPS to form a complicated biofilm community. The growth of biofilm may lead to local nutrient starvation and stimulate lipid accumulation [31]. With our system, we decoupled the influences of ensemble nutrition stress and cell density, and reported greater lipid production of microalgae under high cell density in a local environment. Although further investigation is needed to understand the inter- and intra-cellular mechanisms of the influence of cell density on lipid production, we demonstrated that a chip can be used to monitor microalgae growth with a high throughput and evaluate the lipid content. We conducted tests to compare the growth rate and lipid content with a simultaneous comparison of cell density.

As microalgae in a $1.1 \mathrm{~mm}$ well showed the greatest oil content, we conducted a subsequent experiment on our $1.1 \mathrm{~mm}$ chip to study the effect of UV-C mutagenesis on the chip. Tests showed that UV irradiation of various algae species improves the cell growth and lipid accumulation of microalgae and results in a high lipid-producing strain [32].

Appropriate UV exposure causes random mutagenesis in microalgae, which is caused mainly by the alteration of the DNA of the organism; the UV exposure induces either the formation of thymine dimers that cause a transition of DNA base pairs, or the deletion of base pairs. This genetic alteration further results in an over-expression of nitrate reductase (NR) in the mutant strain that contributes to an increased growth rate [33]. B. braunii were seeded on a chip and irradiated with UV-C light (Philips TUV UV-C TL-D, 36W) for 5, 10 and $15 \mathrm{~min}$ on the first day. The growth rate and lipid content were calculated from 60 samples (20 in each chip) and compared to a control chip that was unexposed to UV-C (Figure 3C,D). From the curve of growth rate, we observed on the fourteenth day chlorophyll intensity values of $410.48 \pm 29.7,561.84 \pm 28.7,504.84 \pm 28.76$, and $381.74 \pm 28.78$, respectively, from UV exposure of 5 and $10 \mathrm{~min}$, control, and $15 \mathrm{~min}$. The lipid contents on the fourteenth day of culture were found to be $1.61 \pm 0.31,2.40 \pm 0.16$, $1.45 \pm 0.27$, and $1.92 \pm 0.64$, respectively (Figure 3B). These results indicate that, in our hanging-drop chip with $B$. braunii algae culture, the 5 min UV-C exposure was considered to be the most efficient, increasing both the growth rate by $36.87 \%$ and the lipid content by $49.02 \%$. The greater lipid content might be directly associated with a specific mutagenesis of the microalgae. The greater growth rate caused by mutagenesis might also have led to a deficiency of nutrients, which caused nitrogen starvation and further induced an increased lipid content [34].

Our data also showed that an excessive dose of UV exposure can lead to undesired effects on the microalgae, such as a small growth rate and lipid content (Figure 3C,D). UV-C exposure can degrade the algal photosynthetic apparatus and pigment content; the oxidative stress and genotoxicity effects generated by UV exposure can further trigger cellular lethality and senescence [35]. With our developed system, in addition to screening parameters simultaneously for cell growth and lipid productivity, our microfluidic platform can be applied to study the impact of UV toxicity.

In addition to the procedure for optimization, we could easily select an algae mutant from each individual well. For instance, a scatter plot of 20 samples from one experiment was taken on the fourteenth day; the data present the lipid content of microalgae in different samples, which show an uneven distribution under each mutation condition (Figure 3D). Once microalgae with a high lipid content are determined, in contrast to a sophisticated algae extraction process [36], the desired microalgae for further studies can be easily extracted using a $1 \mathrm{~mL}$ pipette without affecting the other strains.

We further conducted an experiment on our modified chip to study the effect of the presence and absence of light intensity (Figure 4). On comparison of the fluorescent intensity value of chlorophyll between the regions that were exposed and unexposed to warm white light (1500 lux for 12/12 h cycle), the results showed an initial intensity value of 264 (A.U.) in the region with light and 255 (A.U.) in the region without light. On the fourteenth day of culture the exposed and unexposed regions with light of the specified intensity showed mean intensity values (in A.U.) of $1466.03 \pm 447.00$ and $386.25 \pm 42.19$ in regions of the presence and absence of light, respectively (Figure $4 \mathrm{C}$ ); the lipid content on 
the fourteenth day of culture was found to be $2.09 \pm 0.30786$ and $1.68 \pm 0.29$, respectively. The algae in a region exposed to light showed 2.27 times the cell growth of algae in the unexposed region, which showed slow growth, but in the lipid content result there was only a 19.6\% difference in lipid content between exposed and unexposed regions (Figure 4B). The results support previous findings, which indicated that the energy produced during high light intensity was used for cell division instead of being stored in the form of lipids, whereas in the absence of light the cells do not go through photo-oxidation, which results in the production of a greater lipid content [37]. These results indicate that our hanging-drop chip can be used to define the light conditions to optimize oil productivity in microalgae. The illumination intensity in regular bioreactors, however, alters when the microalgal density increases over time, which makes it difficult to apply identical conditions to all algal cells in a large culture system [20]. It is worthy of mention, though, that this device can be used to screen culturing parameters for rapid side-by-side comparisons between growth and oil production; more practical considerations and larger-scale tests are required to apply the outcome further for industrial culturing.

A

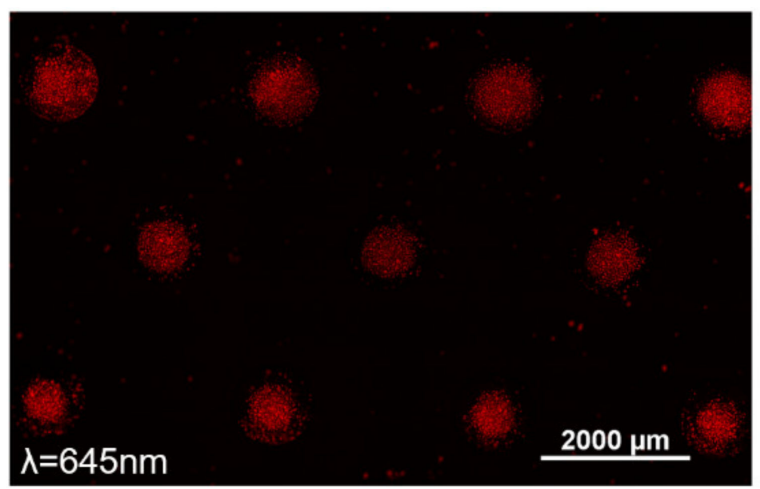

C

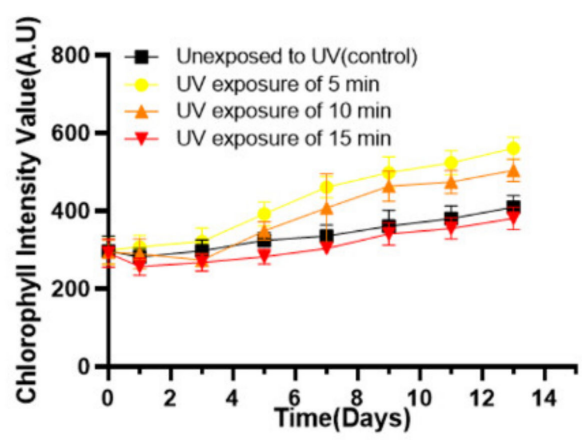

B
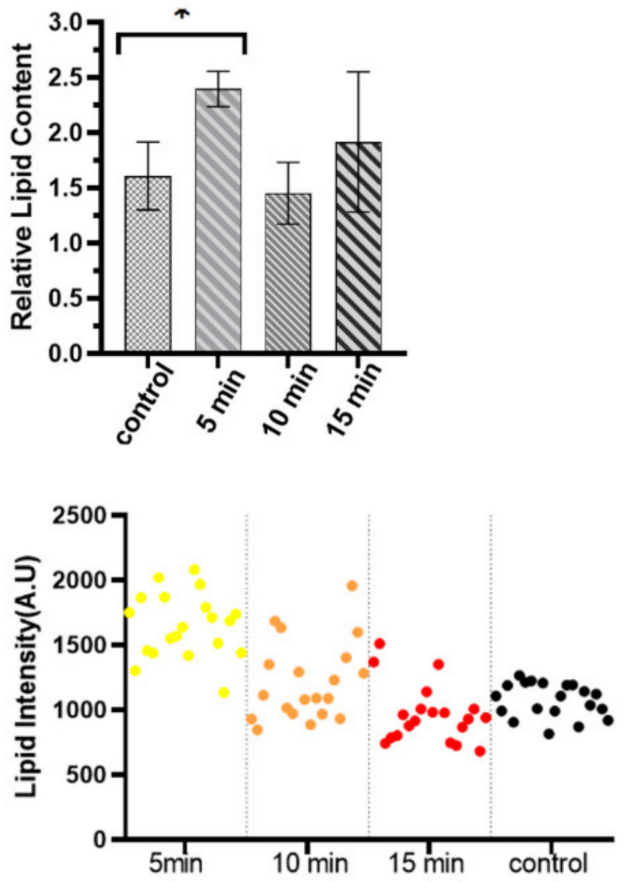

Figure 3. B. braunii treated with a UV mutagenesis procedure on a chip, and its lipid content comparison. (A) Representative images of algal cells in the chip observed at wavelength $645 \mathrm{~nm}$ on its fourteenth day of culture. (B) Quantification of lipid content of three UV-C exposures of a chip $-5,10$ and $15 \mathrm{~min}$, with unexposed chip as a control $(*$ indicated $p$-value $<0.05$, $n=60$ ). (C) Comparison of growth curves of three UV-C chips with exposures 5,10 and 15 min with an unexposed chip as a control $(n=60)$. (D) Scatter plot of the mean intensity of Nile-stained algal cells shows a variation in lipid production with different UV exposure ( $n=20$ for each UV irradiance condition). 


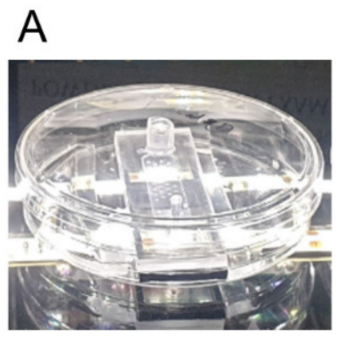

\section{B}
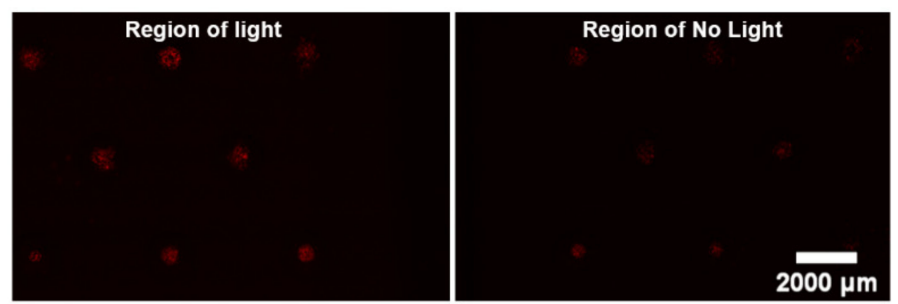

C

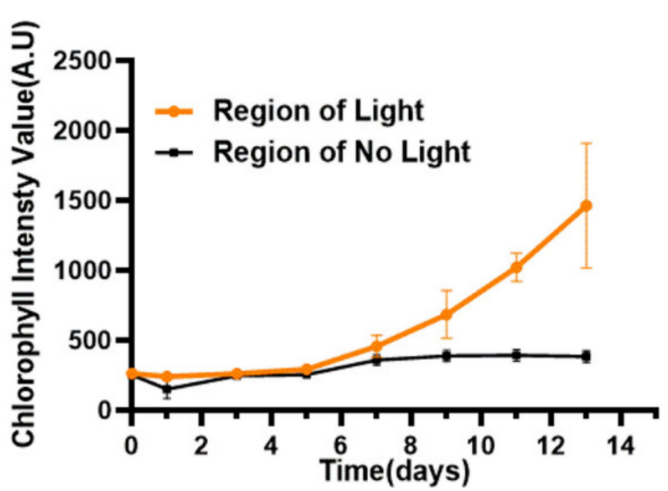

$\mathrm{D}$

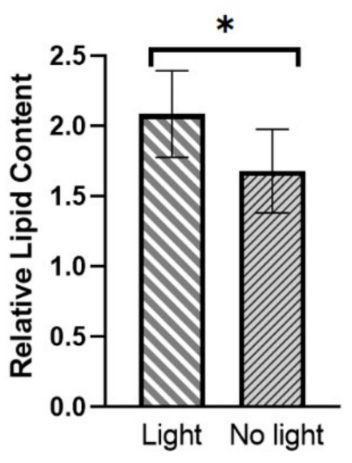

Figure 4. Formation of cell aggregate in the chip with regions of light and no light and the growth curve. (A) Experimental setup of chip with LED light source. (B) Formation of algal cell aggregate within the wells in the chip, which was observed at wavelength $645 \mathrm{~nm}$ with region of presence and absence of light on the fourteenth day of culture. (C) Comparison of curves of growth rate in the presence and absence of light $(n=54)$. (D) Comparison of lipid content of algae grown in a region of the presence and absence of light $\left({ }^{*}\right.$ indicated $p$-value $\left.<0.05, n=54\right)$.

\section{Conclusions}

In this study, we have developed a hanging-drop microfluidic device for the highthroughput screening of microalgae, based on the growth rate and lipid content. In contrast to previous microfluidic approaches $[19,20,23,26,27]$, we first took advantage of the easily accessible hanging drop as a separate bioreactor for algae culturing. By modulating the design of the hanging-drop chip, we easily customized the culture parameters, such as the cell density and illumination. We found, under our experimental conditions, that the clustering of microalgae was associated with enhanced lipid production. Using our hanging-drop chip, we also demonstrated the process for optimizing the UV dosage for mutagenesis to increase the algae growth rate and lipid content simultaneously. Moreover, integrated with a high-throughput microalgae physiology monitored in situ, we directly selected the desired specimens with a laboratory pipette due to the semi-open nature of the hanging drops. Although more studies are required to expand the outcomes of this study for algae cultivation, based on our obtained results, our easily accessible microfluidic system can accelerate the mutation breeding of microalgae and is expected to facilitate the screening process further for microalgae biofuel production.

Author Contributions: S.M.: Investigation, Writing. Y.-J.L.: Conceptualization, Writing and editing. C.-S.C.: Conceptualization, Writing, Resources. D.-J.Y.: Conceptualization, Writing, Resources. All authors have read and agreed to the published version of the manuscript.

Funding: This research was supported by grants from Ministry of Science and Technology, Taiwan (MOST 108-2221-E-007-091-MY2, MOST 109-2112-M-007-003, MOST 110-2217-E-007-003-MY3. Y.-J. Liu was supported by grant from the Ministry of Economic Affairs (MEA), Taiwan (No. 110-EC-17-A22-0525).

Institutional Review Board Statement: Not applicable.

Informed Consent Statement: Not applicable. 
Data Availability Statement: Data will be available from authors upon request.

Conflicts of Interest: The authors declare no conflict of interest.

\section{References}

1. Houghton, J. Global warming. Rep. Prog. Phys. 2005, 68, 1343. [CrossRef]

2. Chisti, Y. Biodiesel from microalgae. Biotechnol. Adv. 2007, 25, 294-306. [CrossRef]

3. Heredia-Arroyo, T.; Wei, W.; Hu, B. Oil Accumulation via Heterotrophic/Mixotrophic Chlorella protothecoides. Appl. Biochem. Biotechnol. 2010, 162, 1978-1995. [CrossRef]

4. Ramli, U.S.; Salas, J.J.; Quant, P.A.; Harwood, J.L. Use of metabolic control analysis to give quantitative information on control of lipid biosynthesis in the important oil crop, Elaeis guineensis (oilpalm). New Phytol. 2009, 184, 330-339. [CrossRef]

5. Kaenchan, P.; Gheewala, S.H. A review of the water footprint of biofuel crop production in Thailand. J. Sustain. Energy Environ. 2013, 4, 45-52.

6. Searchinger, T.; Heimlich, R.; Houghton, R.A.; Dong, F.; Elobeid, A.; Fabiosa, J.; Tokgoz, S.; Hayes, D.; Yu, T.-H. Use of U.S. Croplands for Biofuels Increases Greenhouse Gases Through Emissions from Land-Use Change. Science 2008, 319, $1238-1240$. [CrossRef]

7. Banerjee, A.; Sharma, R.; Chisti, Y.; Banerjee, U.C. Botryococcus braunii: A Renewable Source of Hydrocarbons and Other Chemicals. Crit. Rev. Biotechnol. 2002, 22, 245-279. [CrossRef]

8. Metzger, P.; Casadevall, E.; Pouet, M.; Pouet, Y. Structures of some botryococcenes: Branched hydrocarbons from the b-race of the green alga Botryococcus braunii. Phytochemistry 1985, 24, 2995-3002. [CrossRef]

9. Metzger, P.; Largeau, C. Botryococcus braunii: A rich source for hydrocarbons and related ether lipids. Appl. Microbiol. Biotechnol. 2004, 66, 486-496. [CrossRef] [PubMed]

10. Borowitzka, M.A. Microalgae in medicine and human health: A historical perspective. In Microalgae in Health and Disease Prevention; Elsevier: Amsterdam, The Netherlands, 2018; pp. 195-210.

11. Yamamoto, S.; Mandokoro, Y.; Nagano, S.; Nagakubo, M.; Atsumi, K.; Watanabe, M.M. Catalytic conversion of Botryococcus braunii oil to diesel fuel under mild reaction conditions. Environ. Boil. Fishes 2014, 26, 55-64. [CrossRef]

12. Chisti, Y. Biodiesel from microalgae beats bioethanol. Trends Biotechnol. 2008, 26, 126-131. [CrossRef] [PubMed]

13. Simionato, D.; Basso, S.; Giacometti, G.M.; Morosinotto, T. Optimization of light use efficiency for biofuel production in algae. Biophys. Chem. 2013, 182, 71-78. [CrossRef] [PubMed]

14. Singh, S.; Singh, P. Effect of temperature and light on the growth of algae species: A review. Renew. Sustain. Energy Rev. 2015, 50, 431-444. [CrossRef]

15. Juneja, A.; Ceballos, R.M.; Murthy, G.S. Effects of Environmental Factors and Nutrient Availability on the Biochemical Composition of Algae for Biofuels Production: A Review. Energies 2013, 6, 4607-4638. [CrossRef]

16. Srinivas, R.; Ochs, C. Effect of UV-A Irradiance on Lipid Accumulation in Nannochloropsis oculata. Photochem. Photobiol. 2012, 88, 684-689. [CrossRef]

17. Au, S.H.; Shih, S.C.C.; Wheeler, A.R. Integrated microbioreactor for culture and analysis of bacteria, algae and yeast. Biomed. Microdevices 2010, 13, 41-50. [CrossRef]

18. Lee, P.J.; Hung, P.J.; Rao, V.M.; Lee, L.P. Nanoliter scale microbioreactor array for quantitative cell biology. Biotechnol. Bioeng. 2006, 94, 5-14. [CrossRef]

19. Kim, J.; Taylor, D.; Agrawal, N.; Wang, H.; Kim, H.; Han, A.; Rege, K.; Jayaraman, A. A programmable microfluidic cell array for combinatorial drug screening. Lab Chip 2012, 12, 1813-1822. [CrossRef] [PubMed]

20. Dewan, A.; Kim, J.; McLean, R.H.; Vanapalli, S.A.; Karim, M.N. Growth kinetics of microalgae in microfluidic static droplet arrays. Biotechnol. Bioeng. 2012, 109, 2987-2996. [CrossRef] [PubMed]

21. Pan, J.; Stephenson, A.L.; Kazamia, E.; Huck, W.T.S.; Dennis, J.S.; Smith, A.G.; Abell, C. Quantitative tracking of the growth of individual algal cells in microdroplet compartments. Integr. Biol. 2011, 3, 1043-1051. [CrossRef] [PubMed]

22. Qu, B.; Eu, Y.-J.; Jeong, W.-J.; Kim, D.-P. Droplet electroporation in microfluidics for efficient cell transformation with or without cell wall removal. Lab Chip 2012, 12, 4483-4488. [CrossRef]

23. Holcomb, R.E.; Mason, L.J.; Reardon, K.F.; Cropek, N.M.; Henry, C.S. Culturing and investigation of stress-induced lipid accumulation in microalgae using a microfluidic device. Anal. Bioanal. Chem. 2011, 400, 245-253. [CrossRef] [PubMed]

24. Hung, P.J.; Lee, P.J.; Sabounchi, P.; Aghdam, N.; Lin, R.; Lee, L.P. A novel high aspect ratio microfluidic design to provide a stable and uniform microenvironment for cell growth in a high throughput mammalian cell culture array. Lab Chip 2005, 5, 44-48. [CrossRef] [PubMed]

25. Berges, J.A.; Franklin, D.J.; Harrison, P.J. evolution of an artificial seawater medium: Improvements in enriched seawater, artificial water over the last two decades. J. Phycol. 2001, 37, 1138-1145. [CrossRef]

26. Wu, H.-W.; Hsiao, Y.-H.; Chen, C.-C.; Yet, S.-F.; Hsu, C.-H. A PDMS-Based Microfluidic Hanging Drop Chip for Embryoid Body Formation. Molecules 2016, 21, 882. [CrossRef] [PubMed]

27. Cheng, P.; Ji, B.; Gao, L.; Zhang, W.; Wang, J.; Liu, T. The growth, lipid and hydrocarbon production of Botryococcus braunii with attached cultivation. Bioresour. Technol. 2013, 138, 95-100. [CrossRef]

28. Lee, S.J.; Yoon, B.-D.; Oh, H.-M. Rapid method for the determination of lipid from the green alga Botryococcus braunii. Biotechnol. Tech. 1998, 12, 553-556. [CrossRef] 
29. Vigeolas, H.; Duby, F.; Kaymak, E.; Niessen, G.; Motte, P.; Franck, F.; Remacle, C. Isolation and partial characterization of mutants with elevated lipid content in Chlorella sorokiniana and Scenedesmus obliquus. J. Biotechnol. 2012, 162, 3-12. [CrossRef]

30. Fransolet, D.; Roberty, S.; Herman, A.-C.; Tonk, L.; Hoegh-Guldberg, O.; Plumier, J.-C. Increased Cell Proliferation and Mucocyte Density in the Sea Anemone Aiptasia pallida Recovering from Bleaching. PLoS ONE 2013, 8, e65015. [CrossRef] [PubMed]

31. Li, Y.; Gao, K. Photosynthetic physiology and growth as a function of colony size in the cyanobacteriumNostoc sphaeroides. Eur. J. Phycol. 2004, 39, 9-15. [CrossRef]

32. Schnurr, P.J.; Espie, G.S.; Allen, D.G. Algae biofilm growth and the potential to stimulate lipid accumulation through nutrient starvation. Bioresour. Technol. 2013, 136, 337-344. [CrossRef] [PubMed]

33. Arora, N.; Yen, H.-W.; Philippidis, G.P. Harnessing the Power of Mutagenesis and Adaptive Laboratory Evolution for High Lipid Production by Oleaginous Microalgae and Yeasts. Sustain. J. Rec. 2020, 12, 5125. Available online: https://www.mdpi.com/2071 -1050/12/12/5125 (accessed on 14 March 2021). [CrossRef]

34. Noorhana; Nigam, S.; Rai, M.P.; Sharma, R. Effect of Nitrogen on Growth and Lipid Content of Chlorella pyrenoidosa. Am. J. Biochem. Biotechnol. 2011, 7, 124-129. [CrossRef]

35. Borderie, F.; Laurence, A.-S.; Naoufal, R.; Faisl, B.; Geneviève, O.; Dominique, R.; Badr, A.-S. UV-C irradiation as a tool to eradicate algae in caves. Int. Biodeterior. Biodegrad. 2011, 65, 579-584. [CrossRef]

36. Kim, H.S.; Devarenne, T.P.; Han, A. A high-throughput microfluidic single-cell screening platform capable of selective cell extraction. Lab Chip 2015, 15, 2467-2475. [CrossRef] [PubMed]

37. Nzayisenga, J.C.; Farge, X.; Groll, S.L.; Sellstedt, A. Effects of light intensity on growth and lipid production in microalgae grown in wastewater. Biotechnol. Biofuels 2020, 13, 1-8. [CrossRef] 